\title{
Reduced Atherosclerotic Lesion Size in P-Selectin Deficient Apolipoprotein E-Knockout Mice Fed a Chow but Not a Fat Diet
}

\author{
Marie-Claude Bourdillon, ${ }^{1}$ Jacques Randon, ${ }^{1}$ Lydie Barek, ${ }^{1}$ Kazem Zibara, ${ }^{1}$ Chantal Covacho, ${ }^{1}$ \\ Robin N Poston, ${ }^{2}$ Elza Chignier, ${ }^{1}$ and John L McGregor ${ }^{3,4}$ \\ ${ }^{1}$ EA-3740, INSERM-IFR62, Faculté de Médecine Laënnec, Université Claude Bernard Lyon 1, 7 rue Guillaume Paradin, \\ 69372 Lyon, France \\ ${ }^{2}$ Centre for Cardiovascular Biology and Medicine, Guy's Campus, King's College London, London SE1 1UL, UK \\ ${ }^{3}$ INSERM Unit 689, Hospital Lariboisière, Paris, France \\ ${ }^{4}$ Genomics and Atherothrombosis Laboratory, Thrombosis Research Institute, London SW3 6LR, UK
}

Received 15 September 2005; Revised 27 December 2005; Accepted 29 December 2005

Endothelial cells lining atherosclerotic, but not healthy sites, on human arteries express $P$-selectin. We investigated the role of $P$-selectin on the development of vascular lesions in an $\mathrm{ApoE}^{-/-}$male mice. Double-knockout (ApoE ${ }^{-/-}, P^{-s^{-}} \mathrm{sectin}^{-/-}$; $\left.\mathrm{DKO}^{-}\right)$ were compared to single-knockout (ApoE ${ }^{-1-}$; SKO) mice. They were fed a chow or fat diet for 3, 6, 15, and 20 weeks, without any differences in cholesterol levels. DKO mice fed a chow diet exhibited a ratio of lesion area over media lower than SKO mice, for 3 $(P<.03), 6(P<.001)$, and $15(P<.02)$ weeks. DKO mice fed a fat diet showed a lower ratio only at 3 weeks. $P$-selectin deficiency in $\mathrm{ApoE}^{-/-}$mice has a protective effect in atherosclerotic lesions development. Reduction of lesion size depends on diet type and duration. A fat diet could neutralize the beneficial effects of $P$-selectin deficiency, inducing atherosclerotic lesions via probably other adhesion molecules.

Copyright (c) 2006 Marie-Claude Bourdillon et al. This is an open access article distributed under the Creative Commons Attribution License, which permits unrestricted use, distribution, and reproduction in any medium, provided the original work is properly cited.

\section{INTRODUCTION}

Extensive evidence is now available to show that $P$-selectin (CD62P) $[1,2]$ plays a critical role in the homing of leukocytes to sites of inflammation $[3,4]$. Moreover, this adhesion molecule is present in atherosclerotic lesions, but not healthy sites, of human coronaries and carotid vessels [5]. These results have suggested that $P$-selectin may be implicated, together with other adhesion molecules and cofactors, in the initiation and perpetuation of atherosclerotic lesions. Indeed, C57BL/ 6 mice with a single (ICAM-1, $P$-selectin or CD18) or a double deficiency in adhesion molecules (ICAM$1 /$ CD18 or ICAM- $1 / P$-selectin), fed a fat diet, were shown to have a $50 \%$ to $75 \%$ reduction in fatty streak lesions compared to wild-type mice [6]. Furthermore, $P$-selectin was associated with vascular remodelling in mice [7] and rat [8] carotid arteries.

Atherosclerotic mice models $\left(\mathrm{ApoE}^{-/-}, \mathrm{LDLr}^{-/-}\right)$have been shown to closely mimic human lesions [9-11]. Moreover, lesions in these animals can be accentuated by the use of a hypercholesterolemic diet $[12,13]$. However, in a comparative study between ApoE and LDLr deficient mice, it was observed that the total area of atherosclerotic lesions was greater at all times in $\mathrm{ApoE}^{-/-}$than $\mathrm{LDLr}^{-/-}[14,15]$. It is conceivable that the expression and role of adhesion molecules and cofactors may slightly differ between $\mathrm{ApoE}^{-/-}$and $\mathrm{LDLr}^{-/-}$ mice. $P$-selectin, or a combined $P$ - or $E$-selectin, deficiency in an LDLr knockout, was shown to retards the onset of fatty streak in cholesterol-rich fat-fed animals [16, 17]. Moreover, $P$-selectin has also recently been shown to have a protective effect in an ApoE knockout fed a chow diet for a specific period of time $[18,19]$. The aim of this study was to investigate the effect of $P$-selectin deficiency on the development of vascular lesions in ApoE knockout animals fed a chow or a fat diet for different periods of time. Results show that $P$-selectin deficiency, in the ApoE knockout, imparts a protective effect, over a period of up to 15 but not 20 weeks, in mice fed a chow diet. In contrast, this protective effect is only observed at 3 weeks when animals are fed a fat diet. 
MATERIAL AND METHODS

\section{Animals handling}

Surgical procedures and animal care strictly followed the guidelines of the National Institute of Health and Medical Research (Decree no 87-848 of 19th October 1987). All animals, used in this study, were ether-anaesthetised before organ sampling.

\section{Mice}

The generation of the double-target mutation mice model was carried out with two original knockout lines: the Selp $p^{\mathrm{tm} 1 \text { Bay }}[20]$ and the ApoE $E^{\mathrm{tm} l \text { Unc }}[1,21]$. The ApoE deficient mouse was made available to the European Network on Atherosclerosis (ENA) thanks to Dr N. Maeda (University of North Carolina). The Selp ${ }^{\text {tmlBay }}$ line was made available to the European Network on Atherosclerosis (ENA) thanks to Dr A. L. Beaudet (Baylor College of Medicine, Tex, USA). The ApoE deficient mice were created by targeted inactivation of ApoE gene, removing a fragment of the ApoE gene containing part of the exon 3 and part of the intron 3 which was replaced by the neo gene. The Selp ( $P$-selectin) mice were created by target mutation. The $P$-selectin gene was disrupted by the deletion of a $4.5 \mathrm{~kb}$ region containing exons $3-5$. This region was replaced by the Neo $r$ from Pol2neobpA [22]. Originally, ApoE ${ }^{\mathrm{tm} 1 \mathrm{Unc}}$ chimeras were mated to $\mathrm{C} 57 \mathrm{BL} / 6 \mathrm{~J}$ to obtain B6129F1 animals homozygous for the disrupted gene. These founders were backcrossed 6 times to C57BL/6J mice. A redirection by embryo transfer and three additional backcross generations on C57BL/6JIco were conducted before intercrossing to obtain C57BL/6JIco-ApoE ${ }^{\text {tmlUnc }}$ breeding. The C57BL/6JIco-Selp ${ }^{\text {tmlBay }}$ breeding colony was also established after embryo rederivation and backcrossed with C57BL/6J mice (Transgenic Alliance, Iffa Credo SA/Charles River, Lyon, France). Both lines were maintained in specific and opportunistic pathogen-free (SOPF) status by transfer of the SOPD flora and housing in filter-top cage system coupled with laminar flow working station in a full-barrier unit. The double-mutant colony was generated under the same housing conditions. Homozygous C57BL/6JIco-Apo $\mathrm{E}^{\mathrm{tm} 1 \mathrm{Unc}}$ and C57BL/6JIco-Selp ${ }^{\text {tmlBay }}$ were mated to obtain heterozygous mutants. These double heterozygous animals were intercrossed to produce homozygous animals. These animals were identified by a double protocol: total cholesterol-level assay, for ApoE mutants and a PCR genotyping specific for Selp. Total cholesterol measurement, performed on a blood sample collected from the retroorbital sinus of anaesthetised animals at the end of each observation period before sacrifice, was determined using commercially available assay kits (Boehringer Mannheim, France) and expressed in mmol/L. For identification of Selp $P$-selectin mutants, a classic PCR was done on genomic DNA extracted from tail fragments of the C57BL/6JIco-Selp ${ }^{\text {tmlBay }}$. Two separate PCR amplifications, in view of the large size of the deletion $(4.5 \mathrm{~kb})$, were needed for the detection of Pol2neobpA cassette. The sequence and exon of the oligonucleotides (Genosys, Cambridge, UK) were as follows.
PCR1 conducted to analyse the deletion of P-selectin exon 3

5' TGTAAATCAGAAGGAAGTGGC $3^{\prime} P$-selectin exon 3 upstream primer (sense),

5' GTTACTCTTGATGTAGATCTCC 3'P-selectin exon 3 downstream primer (antisense);

PCR2 conducted to analyse the presence of the inserted Pol2neobpa cassette

5' CAACTCATCTGGTTCAGTGC 3'P-selectin exon 2' upstream primer (sense),

5' GATATTGCTGAAGAGCTTGG 3' gene Neo downstream primer (sense).

The following conditions were applied: denaturation $\left(94^{\circ} \mathrm{C}, 3 \mathrm{~min}\right)$, amplification for 35 cycles including denaturation $\left(94^{\circ} \mathrm{C}, 1 \mathrm{~min}\right)$, annealing $\left(56^{\circ} \mathrm{C}\right.$ in PCR1 or $58^{\circ} \mathrm{C}$ in PCR2, $30 \mathrm{~s})$ extension $\left(72^{\circ} \mathrm{C}, 1.30 \mathrm{~min}\right)$, and a final elongation step $\left(72^{\circ} \mathrm{C}, 5 \mathrm{~min}\right)$. Amplification from wild-type $P$ selectin DNA showed a 319 bp fragment with PCR1 but no amplification product was obtained with PCR2. Amplification from heterozygous animals showed a $319 \mathrm{bp}$ fragment (PCR1) and a $1040 \mathrm{bp}$ fragment (PCR2). After amplification from homozygous $P$-selectin mutants, no product was identified with PCR1 while a $1040 \mathrm{bp}$ fragment was identified with PCR2.

Both male ApoE deficient mice $(n=45)$ and double homozygous mutants (C57BL/6JIco-ApoE ${ }^{\text {tmlUnc }}$ and male C57BL/6JIco-Selp $\left.{ }^{\text {tmlBay }}\right)(n=45)$ were weaned at 3 weeks of age and maintained on chow diet for 1 week ("Souriffarat" breeding diet, standard formulation, pellets, irradiated at $25 \mathrm{KGy}$, from Extralabo, France). Following that stage, they either had access ad libitum to a chow (4\% fat, $0 \%$ cholesterol) or a Western-type diet $(21 \%$ fat, $0.15 \%$ cholesterol, special high-fat formulation, powder, irradiated at $25 \mathrm{KGy}$, from UAR, France). Basal observations of control group were made at time 0 in 4-week-old single ApoE deficient and double ApoE/P-selectin deficient mice.

\section{Histological and morphometric analysis}

Animals were sacrificed after been anaesthetised by ether inhalation. The heart, following incision of the thorax, was briefly perfused ( $2 \mathrm{~min}$ ) with $4 \%$ paraformaldehylde in phosphate buffer saline solution. The heart and the contiguous thoracic aorta were then cut off and rapidly embedded in tissue-Tek OCT compound (Miles, Elkhart, Ind). OCTtreated samples were then frozen in liquid nitrogen. Sections ( $8 \mu \mathrm{m}$ thick) were mounted on gelatin-coated slides and stored at $-80^{\circ} \mathrm{C}$. Histological sections were air dried and fixed in cold acetone for $10 \mathrm{~min}$. Standard hematoxylinphloxin-safranin (HPS) staining was performed and lipids were displayed with oil red $\mathrm{O}(\mathrm{ORO})$ staining.

\section{Immunohistochemistry}

Immediately before immunohistochemical staining, frozen sections were air dried for 1 hour at room temperature (RT), 


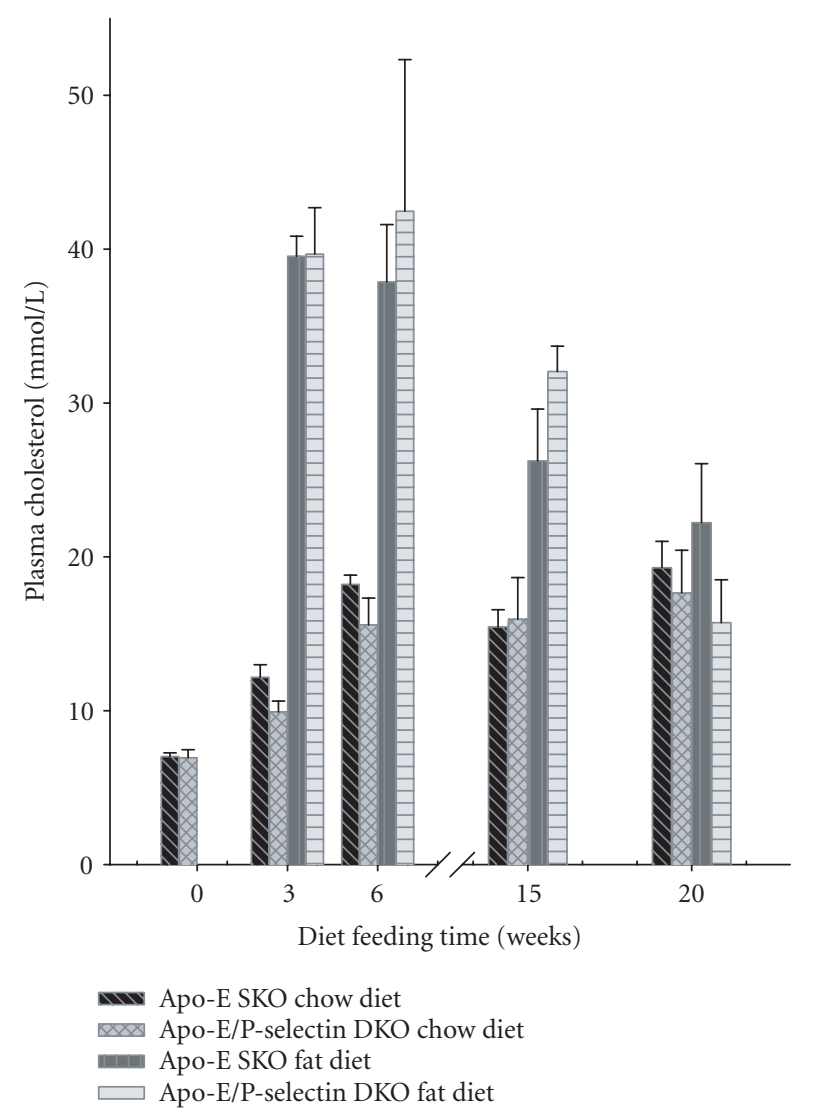

Figure 1: Plasma cholesterol levels in $A p o E^{-/-}(S K O)$ and $A p o E^{-/-}$, $P$-selectin ${ }^{-1-}$ (DKO) mice. Levels of cholesterol for SKO or DKO animals, fed a chow or fat diet, over 0 to 20 weeks. Mean \pm SEM.

fixed in 100\% ice-cold acetone for $5 \mathrm{~min}$, and again air dried for $15 \mathrm{~min}$. A circle was drawn to delimit the tissue using a Dako pen (Dako Laboratories, Denmark). After incubation in blocking solution ( $5 \%$ goat serum, $0.5 \%$ BSA in PBS, Gibco BRL, France; $30 \mathrm{~min}$, RT), sections were incubated with $40 \mu \mathrm{L}$ of the different monoclonal antibodies (mAbs) as described by Onrust et al [23], for the identification of macrophages and endothelial cells. All incubation steps were carried out in a humid chamber at RT, and were followed by washes in $0.5 \%$ BSA in PBS ( 5 min, 3 times).

Macrophages and endothelial cells were, respectively, stained with MOMA-2 (rat antibody directed against murine monocytes/macrophages, Serotec, Oxford, UK) and anti-CD 31 (PECAM-1, Pharmingen, San Diego, Calif) monoclonal antibodies. A nonimmune monoclonal antibody of the same species and class as the MOMA-2 and the anti-CD31 antibodies, a rat IgG2a, (Pharmingen, San Diego, Calif) was used as a negative control. Anti-von Willebrand factor (rabbit polyclonal, Dako, France, at a 1/250 dilution) was used as a marker of endothelial cells. A biotinylated rabbit antirat/mouse adsorbed IgG was used as second antibody (Vector Lab, Burlingame, Calif). Sections were developed using avidin-biotin-horseradish peroxidase complex before AEC (3-amino-9-ethylcarbazole) staining procedures as described [24]. ABC-horseradish peroxidase and AEC chromogen were incubated $30 \mathrm{~min}$ each. Slides with coverslips, using ImmuMount (Shandon Laboratories, Pittsburgh, Pa), were observed after a nuclear counterstaining with hematoxylin.

\section{Quantimetry}

Ratio of lesion area to media area was performed through the use of a Quantimet 600 Leica analyzer (Cambridge, UK). Morphometric analysis of intima lesion area over media area was carried out on the whole circumference of the proximal aortic arch, using a previously described quantification method $[6,9,25]$. Measurements were performed on ORO stained slides for the different weeks of feeding (5 mice per group). Results are expressed as mean ( \pm SEM) of intima/media area ratio. The differences between single (SKO) and double (DKO) knockout mice groups were computed using unpaired Student $t$ test.

\section{RESULTS}

\section{Cholesterol levels}

Basal plasma cholesterol levels of $\mathrm{ApoE}^{-/-}$and $\mathrm{ApoE}^{-/-} / P-$ selectin $^{-/-}$mice showed no difference $(7.01 \pm 1.21 \mathrm{mmol} / \mathrm{L}$ and $6.94 \pm 1.19 \mathrm{mmol} / \mathrm{L}$, resp). These two animal models showed no differences, over a period of time ( 3 to 20 weeks), in cholesterol levels. Animals on a fat diet showed significantly higher cholesterol levels compared to those on chow (Figure 1). Both animal models showed significantly higher cholesterol levels compared to wild-type mice (C57BL6) fed a fat or chow diet (results not shown).

\section{ORO staining and immunohistochemistry}

Oil red $\mathrm{O}$ staining showed different staining patterns between $\mathrm{SKO}$ and DKO mice. Aortic arch lesions staining in fat-fed SKO animals were more extended, in the same time frame, than in DKO animals. Moreover, fat diet accentuated the presence of lipid-loaded cells in both types of animal models (Figure 2, A to H). Macrophages, stained by MOMA-2 monoclonal antibody, are shown binding the endothelial layer and penetrating the intimal lesions in SKO and DKO animals following, respectively, 15- and 20-week chow diet (Figure 3, A to D). Anti-von Willebrand factor and PECAM-1 labelling allowed the identification of the endothelial cell layer present over lesion areas (results not shown).

\section{Lesion area/media area}

The protective effect, resulting from $P$-selectin deficiency, is seen in all DKO animals, compared to SKO, fed a chow diet from 3 to 15 weeks. Indeed, at 3, 6, 15, but not 20 weeks, chow-fed DKO mice showed a lesion/media area ratio that was significantly lower compared to the SKO. Percentage reduction in lesion area/media area for 3, 6, and 15 weeks was, 


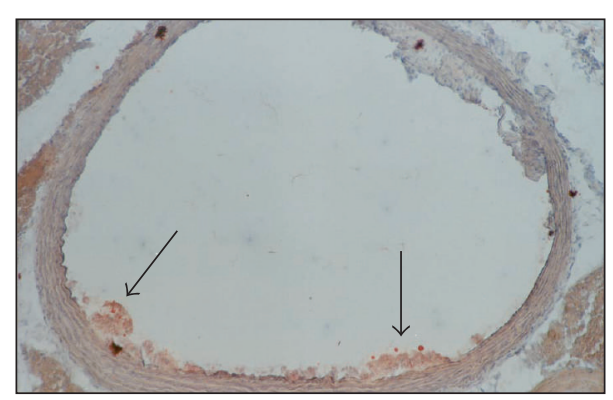

(a)

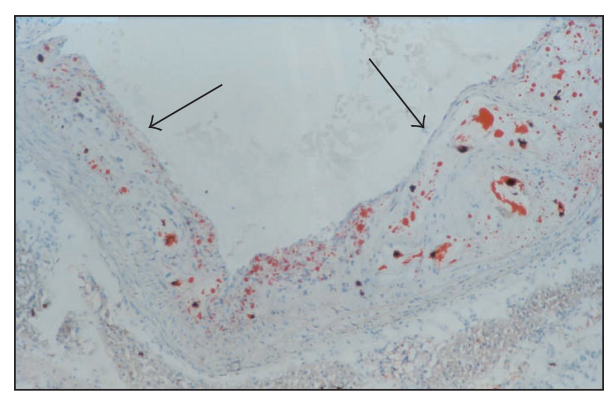

(c)

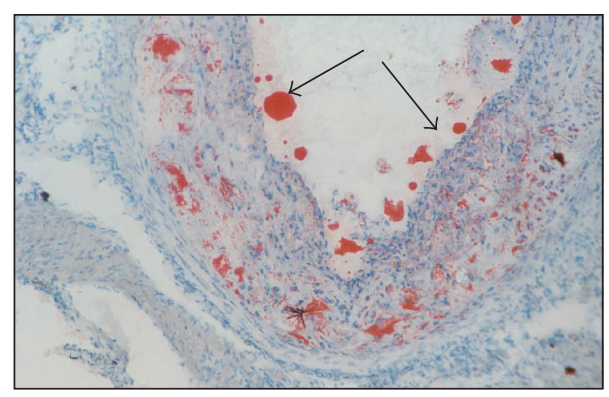

(e)

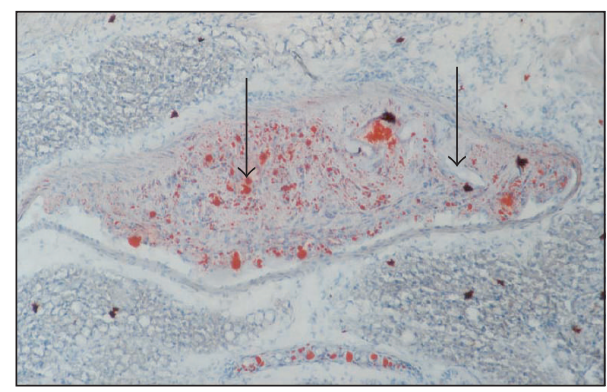

(g)

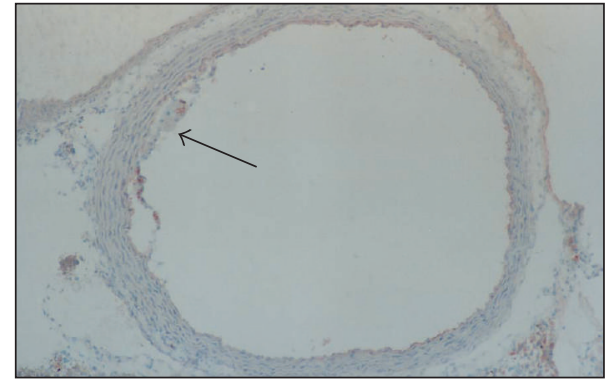

(b)

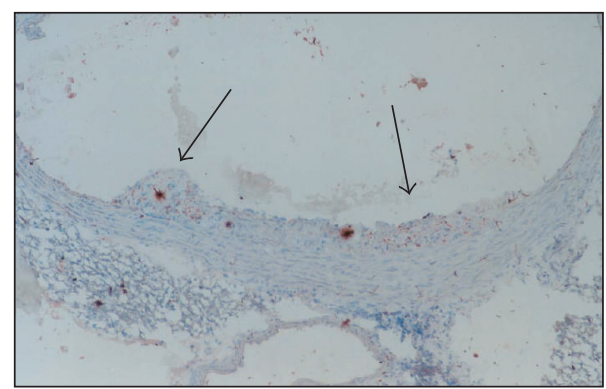

(d)

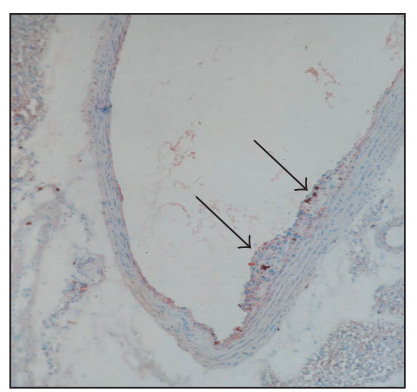

(f)

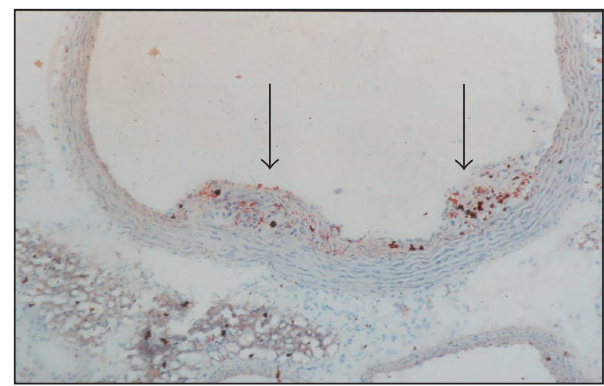

(h)

Figure 2: Oil red $O$ staining of $A p o E^{-/-}$(SKO) and $\mathrm{ApoE}^{-/-}, P$-selectin ${ }^{-/-}$(DKO) mice. The size of ORO-stained aortic lesions is observed to be larger in SKO compared to DKO mice fed a 6- (a-b), 15- (c-d), and 20- (e-h) week fat diet. Lipid ORO-stained droplets are present in aortic lesions from SKO and DKO lesions. At 20 weeks, total lumen obstruction of aortic arch is observed in an ApoE ${ }^{-/-}$animal (g). Black arrows show atherosclerotic lesions. Original magnification: x100 (a, b, f, g, h) and x250 (c, d, e).

respectively, 86, 64, and $89 \%$ (Table 1, Figure 4 ). In contrast, the protective effect resulting from $P$-selectin deficiency, in fat-fed DKO animals compared to SKO, was only seen at 3 weeks but not 6,15 , and 20 weeks. Percentage reduction in lesion area/media area for 3 weeks was $78 \%(P<.001)$. However, one should note the existence of a tendency in these fat-fed DKO mice to show lower lesion size compared to the SKO (Table 1, Figure 5). 


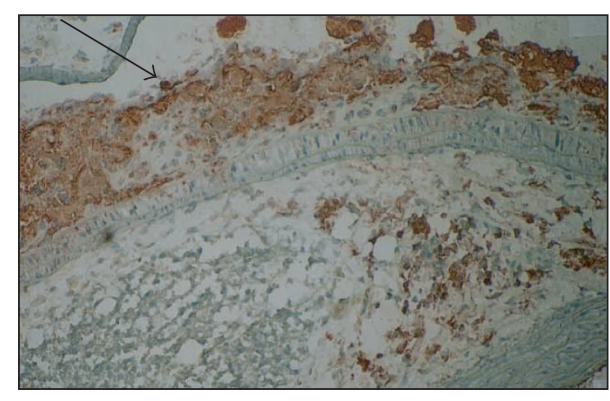

(a)

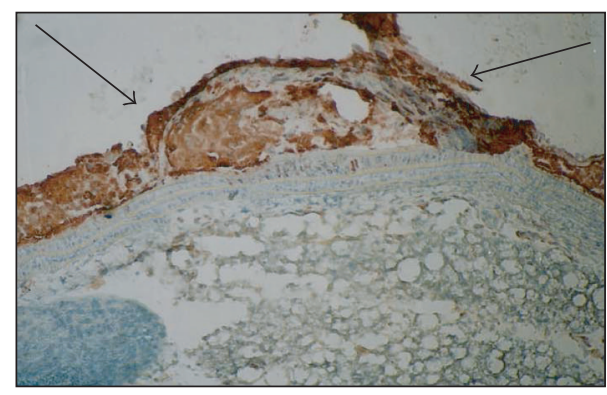

(c)

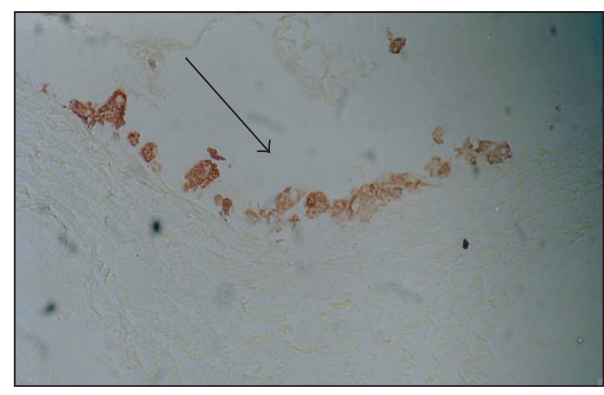

(b)

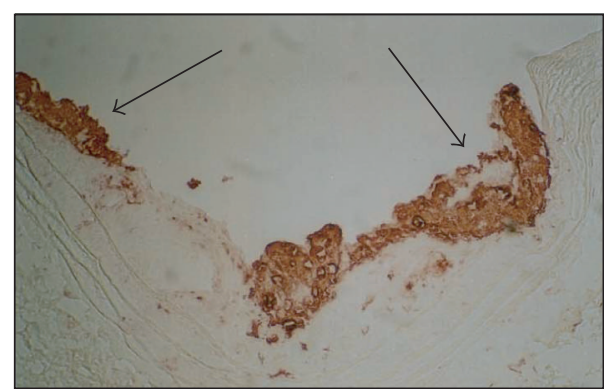

(d)

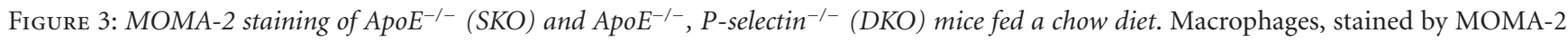
monoclonal antibody, are shown binding the endothelial layer and penetrating the intimal lesions in SKO (a, c) and DKO (b, d) animals following, respectively, 15- (a, b) and 20- (c, d) week chow diet. Black arrows show immunostained macrophages. Original magnification: x250.

TABLE 1: Ratio of Lesion area/Media area. Values are mean \pm SEM (SD) and express ratio (\%) of Lesion area/Media area, measured in $\mu^{2}$. ( $n=5$ mice per group) $p$ values are shown for $\mathrm{ApoE}^{-/-}(\mathrm{SKO})$ and $\mathrm{ApoE}^{-/-} / P$-Selectin ${ }^{-/-}$(DKO) mice fed a chow or fat diet from 0 to 20 weeks.

\begin{tabular}{|c|c|c|c|c|c|c|}
\hline \multirow[b]{2}{*}{$\begin{array}{l}\text { Time } \\
\text { (weeks) }\end{array}$} & \multicolumn{3}{|c|}{ Chow diet } & \multicolumn{3}{|c|}{ Fat diet } \\
\hline & $\mathrm{ApoE}^{-/-}$ & $\begin{array}{c}P \\
(\mathrm{DKO} \text { versus } \mathrm{SKO})\end{array}$ & $\mathrm{ApoE}^{-/-} / P-$ Selectin ${ }^{-/-}$ & $\mathrm{ApoE}^{-/-}$ & $\begin{array}{c}P \\
(\mathrm{DKO} \text { versus } \mathrm{SKO})\end{array}$ & ApoE $^{-/-} / P$-Selectin ${ }^{-/-}$ \\
\hline 0 & $0.95 \pm 0.09(0.20)$ & $P=0.374$ & $0.66 \pm 0.29(0.64)$ & $0.95 \pm 0.09(0.20)$ & $P=0.374$ & $0.66 \pm 0.29(0.64)$ \\
\hline 3 & $10.00 \pm 3.23(7.22)$ & $P<0.029$ & $1.40 \pm 0.29(0.64)$ & $10.77 \pm 1.48(3.31)$ & $P<0.001$ & $2.40 \pm 0.86(1.92)$ \\
\hline 6 & $5.38 \pm 0.51(1.15)$ & $P<0.001$ & $1.90 \pm 0.50(1.13)$ & $18.16 \pm 3.02(6.76)$ & $P=0.239$ & $10.27 \pm 5.42(12.12)$ \\
\hline 15 & $29.00 \pm 5.77(12.90)$ & $P<0.002$ & $3.23 \pm 1.01(2.25)$ & $98.22 \pm 29.51(65.98)$ & $P=0.332$ & $58.77 \pm 24.22(54.15)$ \\
\hline 20 & $66.93 \pm 8.36(18.70)$ & $P=0.289$ & $41.74 \pm 20.59(46.04)$ & $122.91 \pm 23.34(52.19)$ & $P=0.059$ & $43.59 \pm 27.64(61.80)$ \\
\hline
\end{tabular}

\section{DISCUSSION}

This study shows for the first time that the protective effect, imparted by $P$-selectin deficiency in $\mathrm{ApoE}^{-/-}$, is closely tied to the type and duration of the diet. Several lines of evidence back the above statement: (1) $P$-selectin deficiency in $\mathrm{ApoE}^{-/-}$animals shows a significant protection from inti$\mathrm{mal} /$ media remodelling compared to $\mathrm{ApoE}^{-/-}$in mice fed a chow diet. (2) The $P$-selectin protective effect in chow fed animals is significant at $3,6,15$, but not 20 weeks. (3) $P$-selectin deficiency in $\mathrm{ApoE}^{-/-}$animals fed a fat diet showed a protective effect at 3 weeks but not at 6,15 , and 20 weeks.

Atherosclerotic lesions are the result of several events occurring at the level of the vessel wall [26, 27]. Vascular endothelial cells, activated at sites of inflammation, interact with different leukocyte subtypes. Intimal leukocyte accumulation is observed to occur at the onset of the arterial disease [28]. However, as the disease progresses and the vascular wall is remodelled, a reduction in leukocyte recruitment is observed [14]. Such endothelial-leukocyte interactions occur via adhesion molecules, chemokines, and different cofactors that are thought to play a key role in the initiation and perpetuation of atherosclerotic lesions $[29,30]$. Among a number of adhesion molecules, implicated in the homing of leukocytes to sites of inflammation, endothelial $P$ selectin has been reported to mediate transient adherence of monocytes, neutrophils, and activated platelets to endothelial cells [31-34] Such interactions appear to occur via its 


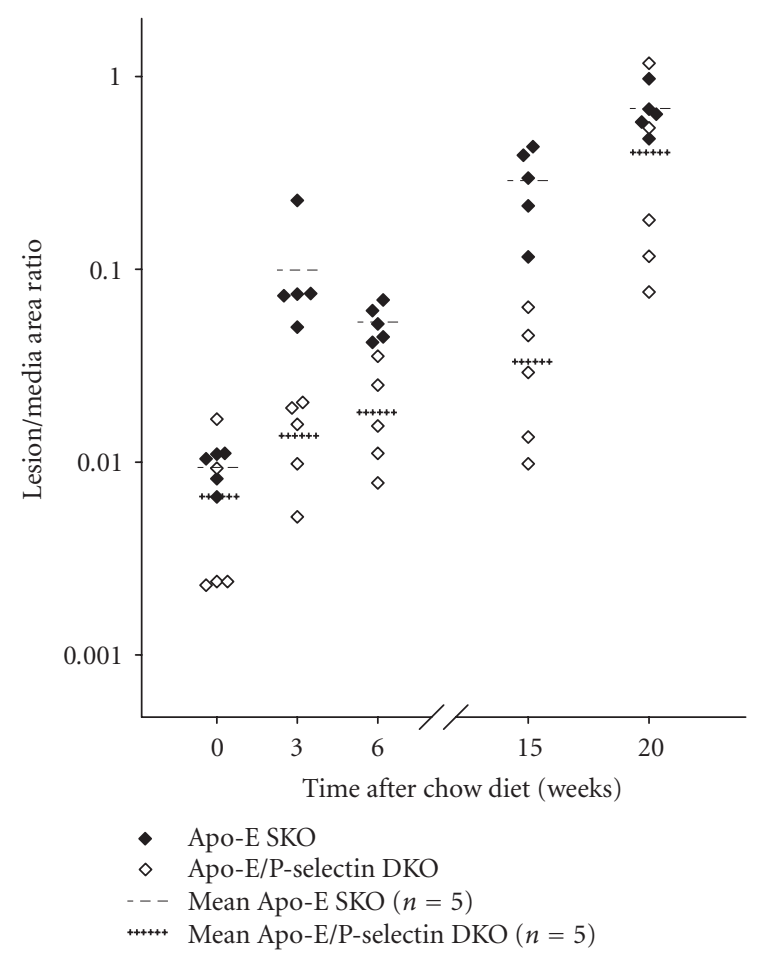

Figure 4: Lesion area in ApoE $E^{-/-}$(SKO) and ApoE $E^{-/-}$, P-Selectin ${ }^{-/-}$ (DKO) mice fed a chow diet. Ratios of lesion area over media area for SKO or DKO animals fed a chow diet, over 0 to 20 weeks. Individual values and means of SKO and DKO area ratios are shown for each time.

ligand (PSGL-1) [35]. Several authors have also reported an increased expression of $P$-selectin in atherosclerotic lesions [6], as well as in vascular remodelling $[7,8]$.

Mice models, with a deficiency of ApoE or LDLr, are thought to mimic vascular lesions observed in human atherosclerosis [15]. One should note that results obtained with the two mice models, namely, ApoE and LDLr deficiency, may slightly differ in size of atherosclerotic lesions [15]. Roselaar et al [14], in a comparative study between ApoE and LDLr deficient mice, observed that the total area of atherosclerotic lesions was greater at all times in $\mathrm{ApoE}^{-/-}$ than $\mathrm{LDLr}^{-/}$. In this study, ApoE deficient animals were compared to those having an ApoE and $P$-selectin deficiency. Results show that $P$-selectin deficiency significantly reduces the intima/media ratio area in the aortic arch regions of $\mathrm{ApoE}^{-/-}$fed a chow diet. However, in our hands, such a reduction was observed for animals fed a chow diet over a period of 3 to 15 weeks but not at 20 weeks. Surprisingly, on feeding these animals a fat diet, the protective effect of $P$ selectin deficiency was limited to those fed for 3 weeks but not at 6,15 , or 20 weeks. Our results, in contrast to the team of Wagner et al [16] working on the same mice models, do not show a protection of $P$-selectin deficiency extending beyond 15 weeks of chow diet. In this study, we also observe that a fat diet can overcome any protective effect of $P$-Selectin after feeding for periods going over 3 weeks. It is conceivable that fat activation may induce endothelial cells to

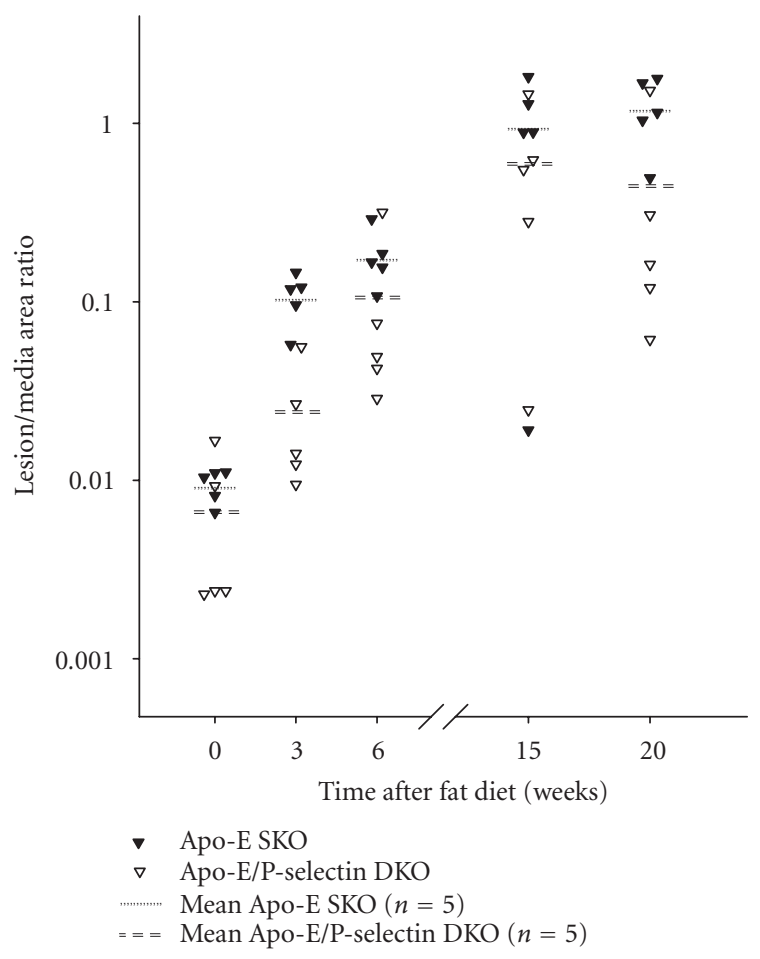

Figure 5: Lesion area in ApoE $E^{-/-}$(SKO) and ApoE ${ }^{-/-}$, P-selectin ${ }^{-/-}$ (DKO) mice fed a fat diet. Ratios of lesion area over media area for SKO or DKO animals fed a fat diet, over 0 to 20 weeks. Individual values and means of SKO and DKO area ratios are shown for each time.

call upon another member of the selectin family, $E$-selectin, to take up the role of $P$-selectin. Indeed, double $P$ - and $E$ selectin deficiency in $\mathrm{LDLr}^{-/-}$mice appears to significantly extend the protective effect of selectins $[17,36]$. However, plaque size and maturation were observed to be independent of $P$-selectin deficiency in LDLr ${ }^{-/-}$mice when these animals were fed a fat diet for an extended period of time (37 weeks) [16]. It is conceivable that certain adhesion receptors, in the absence of selectins, can act as backup molecules to allow the extravasation of monocytes to sites of inflammation at the level of the vessel wall. Recent data, obtained with an ICAM-1 deficiency in $\mathrm{ApoE}^{-/-}$mice, have showed reduced vascular lesions over a greater length of time, compared to $P$-selectin, in fat-fed animals [37]. Indeed, the size of atherosclerotic lesions and the length of protection may greatly depend on the type of adhesion molecule that is being tested in $\mathrm{ApoE}^{-/-}$models in the presence of a chow or fat diet. However, it is interesting to note that $P$-Selectin, but not ICAM-1, is implicated in neointimal growth after carotid injury in ApoE-deficient mice $[38,39]$. Furthermore, intimal lesions are lower in $P$-selectin antagonist-treated rats [8] or mice [40]. Thus, $P$-selectin could be a potential target in diagnostic and therapeutic strategies of atherosclerosis [4144].

Our results suggest that (1) $P$-selectin deficiency displays, under normal conditions of diet, a protective role and delays atherosclerotic plaque formation; (2) the hypercholes- 
terolemic diet triggers other mechanisms and adhesion receptors responsible of the genesis of atherosclerotic plaque; (3) under prolonged hypercholesterolemic injury, $P$-selectin deficiency protective effect is overwhelmed. However, great caution has to be taken in the interpretation of the data between animals fed a chow or a fat diet due to the small number of animals in each group $(n=5)$.

\section{ACKNOWLEDGMENTS}

The authors acknowledge Georges Canard and Dr Patrick Hardy (Transgenic Alliance, Iffa Credo, L'Arbresle) for mice production and colony maintenance. They are indebted to Drs Jean-Claude Bernengo and Catherine Souchier (Centre Commun de Quantimétrie, Université Claude Bernard, Lyon), for helping them in quantimetry computing system. They gratefully thank Simone Peyrol (Centre Commun d'Imagerie Laënnec, Lyon). This work was supported by the French Ministry of Education Scientific Research (Grant MESR ACC-SV9) and by the European Network on Atherosclerosis (ENA, BIOMED 2, Grant no. PL 1195).

\section{REFERENCES}

[1] Johnston GI, Cook RG, McEver RP. Cloning of GMP-140, a granule membrane protein of platelets and endothelium: sequence similarity to proteins involved in cell adhesion and inflammation. Cell. 1989;56(6):1033-1044.

[2] Springer TA. Traffic signals for lymphocyte recirculation and leukocyte emigration: the multistep paradigm. Cell. 1994;76 (2):301-314.

[3] Mayadas TN, Johnson RC, Rayburn H, Hynes RO, Wagner DD. Leukocyte rolling and extravasation are severely compromised in P selectin-deficient mice. Cell. 1993;74(3):541-554.

[4] Subramaniam M, Saffaripour S, Van De Water L, et al. Role of endothelial selectins in wound repair. The American Journal of Pathology. 1997;150(5):1701-1709.

[5] Johnson-Tidey RR, McGregor JL, Taylor PR, Poston RN. Increase in the adhesion molecule P-selectin in endothelium overlying atherosclerotic plaques. Coexpression with intercellular adhesion molecule-1. The American Journal of Pathology. 1994;144(5):952-961.

[6] Nageh MF, Sandberg ET, Marotti KR, et al. Deficiency of inflammatory cell adhesion molecules protects against atherosclerosis in mice. Arteriosclerosis, Thrombosis, and Vascular Biology. 1997;17(8):1517-1520.

[7] Kumar A, Hoover JL, Simmons CA, Lindner V, Shebuski RJ. Remodeling and neointimal formation in the carotid artery of normal and P-selectin-deficient mice. Circulation. 1997;96(12):4333-4342.

[8] Hayashi S, Watanabe N, Nakazawa K, et al. Roles of Pselectin in inflammation, neointimal formation, and vascular remodeling in balloon-injured rat carotid arteries. Circulation. 2000;102(14):1710-1717.

[9] Reddick RL, Zhang SH, Maeda N. Atherosclerosis in mice lacking apo E. Evaluation of lesional development and progression. Arteriosclerosis and Thrombosis. 1994;14(1):141-147.

[10] Piedrahita JA, Zhang SH, Hagaman JR, Oliver PM, Maeda N. Generation of mice carrying a mutant apolipoprotein E gene inactivated by gene targeting in embryonic stem cells. Proceedings of the National Academy of Sciences of the United States of America. 1992;89(10):4471-4475.
[11] Ishibashi S, Brown MS, Goldstein JL, Gerard RD, Hammer RE, Herz J. Hypercholesterolemia in low density lipoprotein receptor knockout mice and its reversal by adenovirusmediated gene delivery. The Journal of Clinical Investigation. 1993;92(2):883-893.

[12] Nakashima Y, Plump AS, Raines EW, Breslow JL, Ross R. ApoE-deficient mice develop lesions of all phases of atherosclerosis throughout the arterial tree. Arteriosclerosis and Thrombosis. 1994;14(1):133-140.

[13] Ishibashi S, Goldstein JL, Brown MS, Herz J, Burns DK. Massive xanthomatosis and atherosclerosis in cholesterol-fed low density lipoprotein receptor-negative mice. The Journal of Clinical Investigation. 1994;93(5):1885-1893.

[14] Roselaar SE, Kakkanathu PX, Daugherty A. Lymphocyte populations in atherosclerotic lesions of and LDL $\mathrm{ApoE}^{-/-}$and LDL receptor $^{-/-}$mice. Decreasing density with disease progression. Arteriosclerosis, Thrombosis, and Vascular Biology. 1996;16(8):1013-1018.

[15] Knowles JW, Maeda N. Genetic modifiers of atherosclerosis in mice. Arteriosclerosis, Thrombosis, and Vascular Biology. 2000;20(11):2336-2345.

[16] Johnson RC, Chapman SM, Dong ZM, et al. Absence of Pselectin delays fatty streak formation in mice. The Journal of Clinical Investigation. 1997;99(5):1037-1043.

[17] Dong ZM, Chapman SM, Brown AA, Frenette PS, Hynes $\mathrm{RO}$, Wagner DD. The combined role of P- and E-selectins in atherosclerosis. The Journal of Clinical Investigation. 1998;102 (1):145-152.

[18] Dong ZM, Brown AA, Wagner DD. Prominent role of Pselectin in the development of advanced atherosclerosis in ApoE-deficient mice. Circulation. 2000;101(19):2290-2295.

[19] Collins RG, Velji R, Guevara NV, Hicks MJ, Chan L, Beaudet AL. P-selectin or intercellular adhesion molecule (ICAM)1 deficiency substantially protects against atherosclerosis in apolipoprotein E-deficient mice. The Journal of Experimental Medicine. 2000;191(1):189-194.

[20] Bullard DC, Qin L, Lorenzo I, et al. P-selectin/ICAM-1 double mutant mice: acute emigration of neutrophils into the peritoneum is completely absent but is normal into pulmonary alveoli. The Journal of Clinical Investigation. 1995;95(4):17821788.

[21] Zhang SH, Reddick RL, Piedrahita JA, Maeda N. Spontaneous hypercholesterolemia and arterial lesions in mice lacking apolipoprotein E. Science. 1992;258(5081):468-471.

[22] Soriano P, Montgomery C, Geske R, Bradley A. Targeted disruption of the $c$-src proto-oncogene leads to osteopetrosis in mice. Cell. 1991;64(4):693-702.

[23] Onrust SV, Hartl PM, Rosen SD, Hanahan D. Modulation of L-selectin ligand expression during an immune response accompanying tumorigenesis in transgenic mice. The Journal of Clinical Investigation. 1996;97(1):54-64.

[24] Hsu SM, Raine L, Fanger H. The use of antiavidin antibody and avidin-biotin-peroxidase complex in immunoperoxidase technics. American Journal of Clinical Pathology. 1981; 75(6):816-821.

[25] Dawson TC, Kuziel WA, Osahar TA, Maeda N. Absence of CC chemokine receptor-2 reduces atherosclerosis in apolipoprotein E-deficient mice. Atherosclerosis. 1999;143(1):205-211.

[26] Ross R. Atherosclerosis-an inflammatory disease. The New England Journal of Medicine. 1999;340(2):115-126.

[27] Shor A, Phillips JI, Ong G, Thomas BJ, Taylor-Robinson D. Chlamydia pneumoniae in atheroma: consideration of criteria for causality. Journal of Clinical Pathology. 1998;51(11):812817. 
[28] O’Brien KD, McDonald TO, Chait A, Allen MD, Alpers CE. Neovascular expression of E-selectin, intercellular adhesion molecule-1, and vascular cell adhesion molecule- 1 in human atherosclerosis and their relation to intimal leukocyte content. Circulation. 1996;93(4):672-682.

[29] Poston RN, Johnson-Tidey RR. Localized adhesion of monocytes to human atherosclerotic plaques demonstrated in vitro: implications for atherogenesis. The American Journal of Pathology. 1996;149(1):73-80.

[30] Iiyama K, Hajra L, Iiyama M, et al. Patterns of vascular cell adhesion molecule- 1 and intercellular adhesion molecule- 1 expression in rabbit and mouse atherosclerotic lesions and at sites predisposed to lesion formation. Circulation Research. 1999;85(2):199-207.

[31] Larsen E, Celi A, Gilbert GE, et al. PADGEM protein: a receptor that mediates the interaction of activated platelets with neutrophils and monocytes. Cell. 1989;59(2):305-312.

[32] Hamburger SA, McEver RP. GMP-140 mediates adhesion of stimulated platelets to neutrophils. Blood. 1990;75(3):550554.

[33] Lasky LA. Selectins: interpreters of cell-specific carbohydrate information during inflammation. Science. 1992;258(5084): 964-969.

[34] Murphy JF, McGregor JL. A peptide (P2) derived from the variable heavy chain of an anti-P-selectin monoclonal antibody (LYP20) inhibits leucocyte adhesion to thrombinactivated platelets and endothelial cells. British Journal of Haematology. 2003;120(4):605-610.

[35] Moore KL, Stults NL, Diaz S, et al. Identification of a specific glycoprotein ligand for P-selectin (CD62) on myeloid cells. The Journal of Cell Biology. 1992;118(2):445-456.

[36] Frenette PS, Wagner DD. Insights into selectin function from knockout mice. Thrombosis and Haemostasis. 1997;78(1):60 64.

[37] Bourdillon M-C, Poston RN, Covacho C, Chignier E, Bricca G, McGregor JL. ICAM-1 deficiency reduces atherosclerotic lesions in double-knockout mice $\left(\mathrm{ApoE}^{-/-} / \mathrm{ICAM}-1^{-/-}\right)$fed a fat or a chow diet. Arteriosclerosis, Thrombosis, and Vascular Biology. 2000;20(12):2630-2635.

[38] Manka D, Collins RG, Ley K, Beaudet AL, Sarembock IJ. Absence of p-selectin, but not intercellular adhesion molecule-1, attenuates neointimal growth after arterial injury in apolipoprotein e-deficient mice. Circulation. 2001;103(7): 1000-1005.

[39] Manka D, Forlow SB, Sanders JM, et al. Critical role of platelet P-selectin in the response to arterial injury in apolipoproteinE-deficient mice. Arteriosclerosis, Thrombosis, and Vascular Biology. 2004;24(6):1124-1129.

[40] Phillips JW, Barringhaus KG, Sanders JM, et al. Single injection of P-selectin or P-selectin glycoprotein ligand-1 monoclonal antibody blocks neointima formation after arterial injury in apolipoprotein E-deficient mice. Circulation. 2003;107 (17):2244-2249.

[41] Molenaar TJ, Twisk J, de Haas SA, et al. P-selectin as a candidate target in atherosclerosis. Biochemical Pharmacology. 2003; 66(5):859-866.

[42] Burger PC, Wagner DD. Platelet P-selectin facilitates atherosclerotic lesion development. Blood. 2003;101(7):2661-2666.

[43] Lutters BC, Leeuwenburgh MA, Appeldoorn CC, Molenaar TJ, Van Berkel TJ, Biessen EA. Blocking endothelial adhesion molecules: a potential therapeutic strategy to combat atherogenesis. Current Opinion in Lipidology. 2004;15(5):545-552.
[44] McGregor L, Martin J, McGregor JL. Platelet-leukocyte aggregates and derived microparticles in inflammation, vascular remodelling and thrombosis. Frontiers in Bioscience. 2006;11:830-837. 


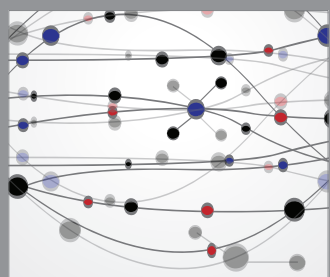

The Scientific World Journal
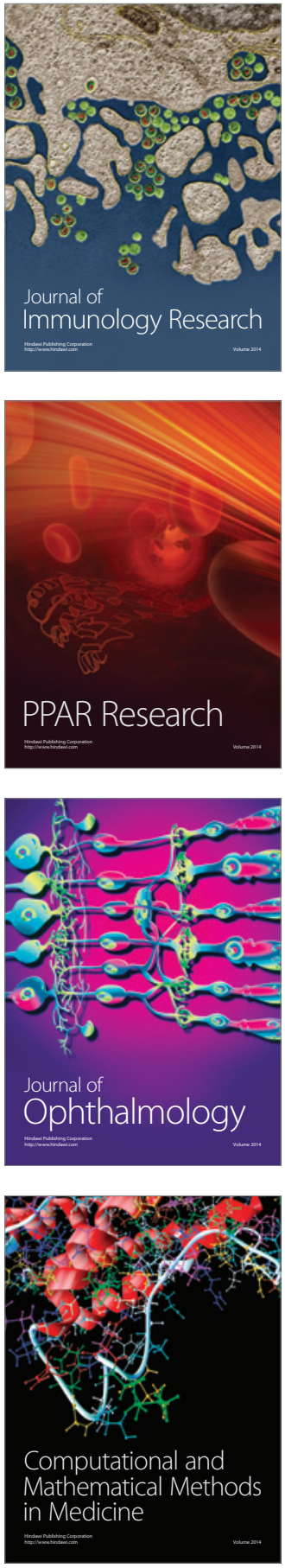

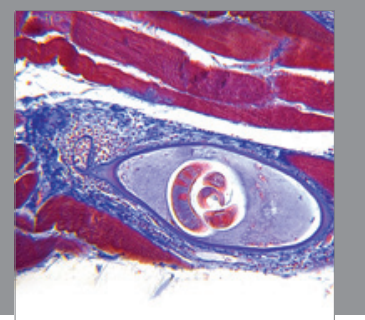

Gastroenterology

Research and Practice
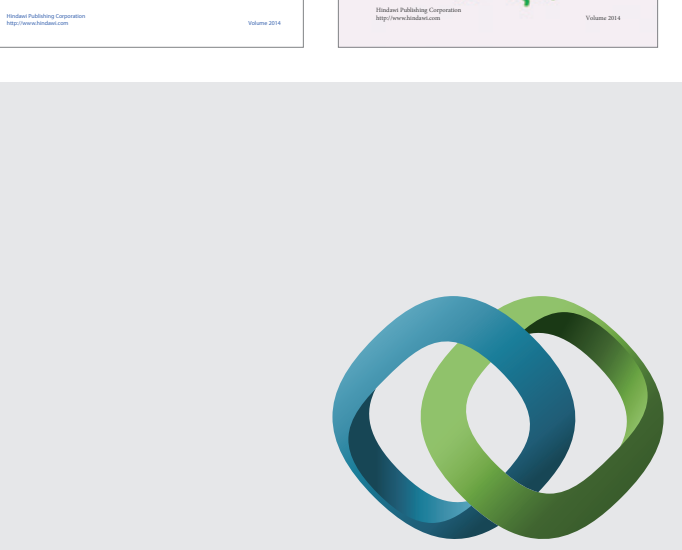

\section{Hindawi}

Submit your manuscripts at

http://www.hindawi.com
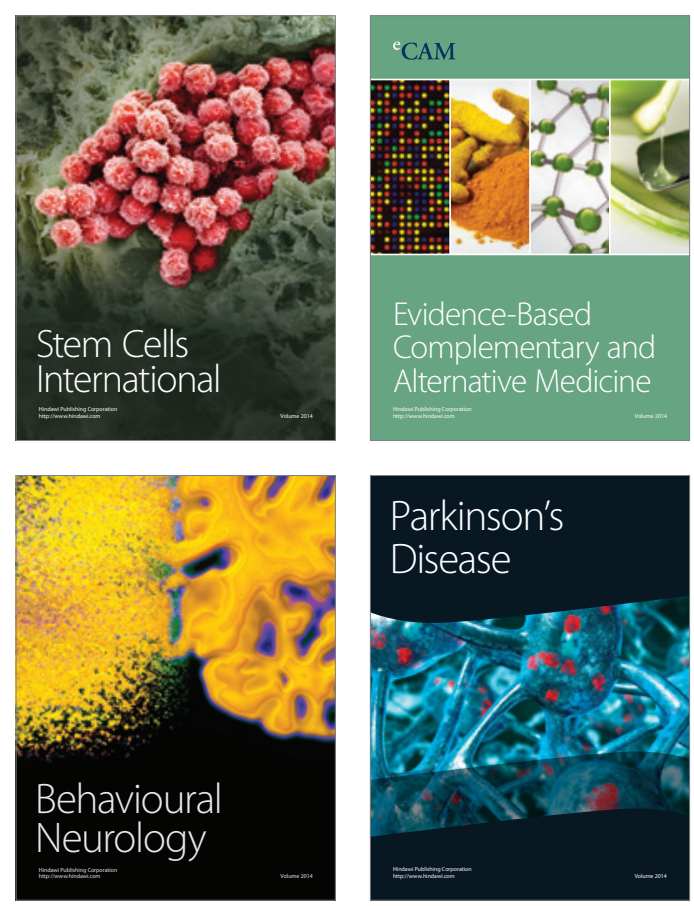

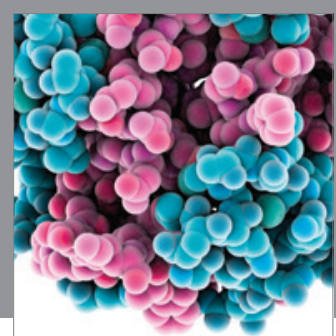

Journal of
Diabetes Research

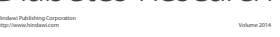

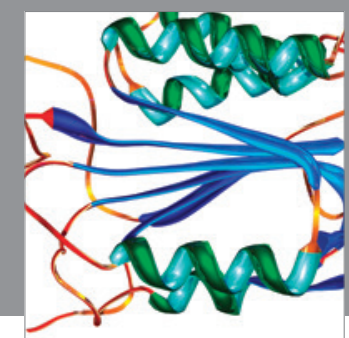

Disease Markers
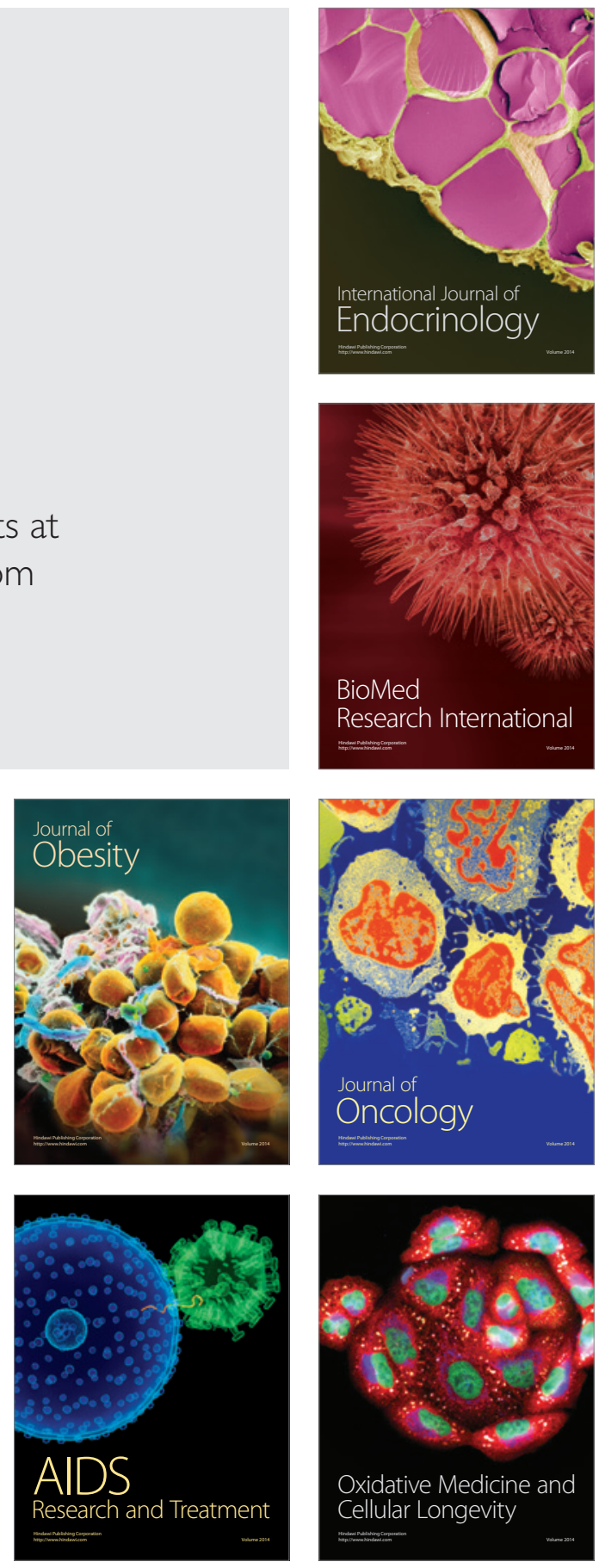